\title{
Retratos da inclusão: o atendimento ao surdo em distintos espaços sociais
}

\author{
Inclusion portraits: the service for the deaf in different social spaces
}

\section{Retratos de la inclusión: la atención al sordo en distintos espacios sociales}

Taline Pereira Chaves'

Universidade Federal da Fronteira Sul, Bolsista de iniciação à docência

Gisleine Sonali Pereira Tonin ${ }^{2}$

Universidade Federal da Fronteira Sul, Estudante

\section{Patrícia Graff ${ }^{3}$}

Universidade Federal da Fronteira Sul, Docente do curso de Pedagogia

Resumo: 0 presente artigo tem como tema de pesquisa a acessibilidade direcionada aos surdos, com o objetivo de compreender como os distintos espaços sociais se organizam para atender às pessoas surdas. Trata-se de uma pesquisa bibliográfica, por meio da análise de estudos acadêmicos, disponíveis no Banco de Teses e Dissertações da CAPES e no IBICT, que abordam a acessibilidade às pessoas surdas, em diferentes espaços da sociedade. Os dados coletados a partir da leitura de cada uma das pesquisas selecionadas foram categorizados, interpretados e analisados. Os estudos apontam para as dificuldades enfrentadas pelas pessoas surdas nos diferentes setores da sociedade, como educação, saúde, lazer e trabalho. Evidenciam a ausência de tradutores/intérpretes de Libras/Língua Portuguesa e de profissionais capacitados em Libras nos espaços sociais, utilizando outras formas de comunicação pouco eficazes para assegurar a inclusão social.

Palavras-chave: Acessibilidade. Surdos. Comunicação.

Abstract: The present article has as research theme accessibility for deaf, with the objective of understand how the different social spaces are organized to meet deaf people. It is a bibliographical research through analysis of academic studies, available at the CAPES Theses and Dissertations Bank and at IBICT, that address the accessibility to deaf people, in different spaces of society. The collected data from the reading of each of the selected researches were categorized, interpreted and

Graduada em Pedagogia pela Universidade Federal da Fronteira Sul; https://orcid.org/0000-0001-6345-4665; http://lattes. cnpq.br/1598091449822794.

2 Graduanda do Curso de Pedagogia da Universidade Federal da Fronteira Sul; https://orcid.org/0000-0002-1833-0652; http:// lattes.cnpq.br/9346288053060369.

3 Doutora em Educação pela Universidade do Vale do Rio dos Sinos; Mestre em Educação nas Ciências pela Universidade Regional do Noroeste do Estado do Rio Grande; https://orcid.org/0000-0002-3315-2401; http://lattes.cnpq.br/5670585241403271. 
analyzed. The studies point to the difficulty faced by deaf people in different sectors of society, such as education, health, leisure and work. Evidence of the absence of translators/interpreters from Libras/ Portuguese Language and of professionals trained in Libras in social spaces, using less effective forms of communication to ensure social inclusion.

Keywords: Accessibility. Deaf. Communication.

Resumen: El presente artículo tiene como tema de investigación la accesibilidad direccionada a los sordos, con el objetivo de comprender cómo los distintos espacios sociales se organizan para atender a las personas sordas. Se trata de una investigación bibliográfica, por medio de análisis de estudios académicos, disponibles en el Banco de Tesis y Disertaciones de la CAPES y en el IBICT, que abordan la accesibilidad para las personas sordas, en diferentes espacios de la sociedad. Los datos recogidos a partir de la lectura de cada una de las investigaciones seleccionadas fueron categorizados, interpretados y analizados. Los estudios apuntan hacia las dificultades enfrentadas por personas sordas en los diferentes sectores de la sociedad, como educación, salud, ocio y trabajo. Se evidencia la ausencia de traductores/intérpretes de Lenguaje de señas (en Brasil Libras)/Lengua portuguesa y de profesionales capacitados en Lenguaje de señas en los espacios sociales, utilizando otras formas de comunicación poco eficaces a la hora de garantizar la inclusión social.

Palabras clave: Accesibilidad. Sordos. Comunicación.

Recebido em 9 de julho de 2018

Aceito em 12 de março de 2019

Publicado em 19 de março de 2019

\section{INTRODUÇÃO}

Vivemos, na atualidade, um momento de conscientização social frente a questões que se referem à acessibilidade e à inclusão das pessoas com deficiência; neste texto, interessam-nos, especialmente, nas questões voltadas à surdez. Uma multiplicidade de notícias retrata iniciativas de distintas organizações para a promoção da acessibilidade. Nesse cenário entendemos que, aos poucos, começa-se a incorporar a necessidade de produzir as condições materiais para o acesso das pessoas com deficiência aos diferentes espaços sociais. Destacamos, aqui, algumas notícias que contextualizam o cenário atual. Em 2014, a companhia aérea Gol lançou um projeto-piloto cuja meta era, até o final do mesmo ano, disponibilizar 10 terminais, em diferentes aeroportos, para o atendimento em Língua Brasileira de Sinais (Libras) (GAZZONI, 2014). A Caixa Econômica Federal, por sua vez, vem capacitando seus funcionários em Libras - desde o ano 2008 -, além de possuir um sistema de Discagem Direta Gratuita (DDG), utilizando um aparelho específico com visor e teclado, que facilita o atendimento aos clientes 
surdos. Ainda em 2014 foi divulgada, em rede nacional de televisão, uma campanha publicitária que retrata o atendimento, em Libras, de um casal de surdos, destacando que a CAIXA possui 4.000 empregados capacitados para atender a esse público (CAIXA..., 2016).

Notícias como essas nos fazem pensar que o imperativo da inclusão (LOPES et al., 2010) - cujas condições de possibilidade vêm se instituindo desde a década de 1990, com o objetivo de produzir uma educação para todos - vem, gradualmente, sendo materializado por meio da acessibilidade, quando ela passa a se tornar uma preocupação nos diferentes setores da sociedade, por meio de iniciativas que proporcionem acesso a distintos espaços sociais. Essas iniciativas se tornam ainda mais importantes quando atentamos para os dados do último censo demográfico, divulgado pelo Instituto Brasileiro de Geografia e Estatística (IBGE), que apontam para a existência de 9,7 milhões de pessoas com algum tipo de deficiência auditiva no país (BRASIL, 2012). Importa marcar, nesse início, que entendemos a surdez a partir da perspectiva da diferença, como um marcador cultural (LOPES; VEIGA-NETO, 2006) que circunscreve um conjunto de sujeitos a um grupo identitário específico - embora ela seja retratada, pela legislação e pela estatística, como uma deficiência. Nessa esteira, a surdez deixa de ser vista como uma deficiência e possibilita o direcionamento de outras práticas para esses indivíduos. Desse modo, no âmbito deste texto, o uso do termo deficiência, para referir aos surdos, limita-se aos aspectos legais que atendem a esse grupo identitário.

No Brasil, um conjunto de leis e decretos assegura os direitos de igualdade de oportunidades para todos, como refere a Lei n. 13.146, de 6 de julho de 2015, que institui o Estatuto da Pessoa com Deficiência. 0 Estatuto evidencia que cabe ao Poder Público e a seus órgãos garantir a integração social e a cidadania das pessoas com deficiência, na área da educação, da saúde, do lazer, do trabalho, entre outras. A Constituição Federal, em 1988, já fazia menção a esses direitos ao afirmar, em seu Artigo $5^{\circ}$, que "todos são iguais perante a Lei, [garantindo aos indivíduos] a inviolabilidade do direito à vida, à liberdade, à igualdade, à segurança, e à propriedade." (BRASIL, 1988). Além disso, o Artigo $9^{\circ}$ do Decreto n. 6.949, de 25 de agosto de 2009 - que promulga a Convenção sobre os Direitos das Pessoas com Deficiência -, determina a garantia, pelos Estados-partes, de acesso das pessoas com deficiência "ao meio físico, ao transporte, à informação e comunicação, inclusive aos sistemas e tecnologias da informação e comunicação." (BRASIL, 2009). Assim, inviabilizar as condições adequadas de acessibilidade às pessoas com deficiência não está de acordo com os direitos declarados por lei, o que dificulta a inclusão social. Diante desse cenário, a acessibilidade direcionada às pessoas surdas constitui o tema central desta pesquisa.

Para desenhar os primeiros contornos sobre essa temática (acessibilidade), parece-nos importante destacar o Decreto n. 5.626, de 22 de dezembro de 2005, que regulamenta a Lei n. 10.436, de 24 de abril de 2002, e orienta sobre o uso e a difusão da Língua Brasileira de Sinais (Libras), reconhecendo-a como a primeira língua dos surdos. 0 
referido Decreto estabelece a inclusão da Libras como componente curricular obrigatório para os cursos de formação de docentes e Fonoaudiologia, e a garantia de tradutores/intérpretes de Língua Brasileira de Sinais/Língua Portuguesa nas instituições escolares, visando ao acesso dos surdos à educação (BRASIL, 2005). Partindo dessa explanação e entendendo que a inclusão não é tarefa exclusiva da escola, mas das distintas instâncias e organizações que compõem a sociedade, produzimos o seguinte problema central para esta pesquisa: como os diferentes espaços sociais realizam o atendimento às pessoas surdas?

A partir desse problema central, o objetivo principal deste estudo consiste em compreender como os distintos espaços sociais se organizam para atender às pessoas surdas. Para isso, propõe-se, partindo de um conjunto de estudos acadêmicos sobre o tema, identificar as funções que os tradutores/intérpretes de Libras/Língua Portuguesa exercem na sociedade; conhecer o modo como ocorre o atendimento aos surdos em diferentes ambientes; e verificar se há, além dos tradutores/intérpretes de Libras/Língua Portuguesa, outras formas de facilitar a comunicação com as pessoas surdas.

Feita a apresentação da pesquisa, sinalizamos que o artigo está organizado em quatro seções, sendo a primeira delas constituída pela introdução do tema composta pela justificativa, pelos objetivos e pela pergunta da pesquisa. Na segunda seção é apresentada a metodologia que utilizamos para a realização do estudo. A terceira seção é composta pelos resultados das análises e discussões empreendidas sobre os materiais escolhidos para constituir o corpus da pesquisa. $E$ a quarta seção do artigo é constituida pelas considerações finais.

\section{PROCEDIMENTOS METODOLÓGIICOS}

Esta pesquisa é produzida a partir de uma abordagem qualitativa, com o intuito de responder à pergunta central de pesquisa: como os diferentes espaços sociais realizam o atendimento às pessoas surdas? A abordagem qualitativa, de acordo com Minayo, Deslandes e Gomes (2002, p. 21), "trabalha com o universo de significações, motivos, aspirações, crenças, valores e atitudes, o que corresponde a um espaço mais profundo das relações, dos processos e dos fenômenos que não podem ser reduzidos à operacionalização de variáveis." Essa abordagem nos parece apropriada para este estudo, pois tem a preocupação com a compreensão da relação humana com certos aspectos da realidade.

A partir dessa perspectiva, realizamos um levantamento bibliográfico de estudos já elaborados e publicados sobre o tema. Esse tipo de pesquisa, conforme Marconi e Lakatos (2002, p. 71), tem como objetivo "colocar o pesquisador em contato direto com tudo o que foi escrito, dito, ou filmado sobre determinado assunto." Para a produção de dados para a 
pesquisa foram realizadas buscas na base de dados do Instituto Brasileiro de Informação em Ciência e Tecnologia (IBICT), no portal de periódicos da Coordenação de Aperfeiçoamento de Pessoal de Nivel Superior (Capes) e do Banco de Teses e Dissertações da Capes, por meio dos seguintes descritores: acessibilidade e Libras; acessibilidade e surdez; acessibilidade e surdos; inclusão e Libras; atuação intérpretes de Libras e inclusão surdos.

No primeiro momento, a seleção foi realizada pela leitura dos títulos, encontrando 86 estudos, distribuídos entre artigos, dissertações e teses, com período de publicação entre 2005 e 2017. Destacamos que o marco temporal iniciado em 2005 provavelmente se justifica pela organização e publicação do Decreto n. 5.626/2005. Entre os estudos catalogados, foram excluídos os trabalhos repetidos, permanecendo 36 estudos, após uma primeira seleção pelos títulos. A partir da leitura dos resumos foram selecionados 14 estudos, entre eles: quatro artigos, uma monografia de especialização, oito dissertações e uma tese relacionados ao tema, que compõe a superfície analítica desta pesquisa. Como critério de seleção, permaneceram apenas os estudos que atendem aos objetivos e à pergunta da pesquisa.

A leitura, na íntegra, desses estudos, possibilitou a elaboração de categorias analíticas, a partir de aspectos em comum entre eles. Assim, a análise foi organizada a partir das três categorias que emergiram dos materiais. Para dar visibilidade às categorias, organizamos quadros com excertos dos materiais, dispostos no texto à medida que nos ajudam a fazer as discussões. Na primeira categoria, intitulada os tradutores/intérpretes de Língua Brasileira de Sinais/Língua Portuguesa, analisamos a presença ou a ausência desses profissionais nos diferentes espaços da sociedade e a importância deles para a inclusão dos surdos. Na segunda categoria, intitulada as estratégias de comunicação, identificamos como ocorre o atendimento dos surdos em diferentes espaços sociais, e se as estratégias utilizadas são eficazes para a comunicação. Na terceira categoria, intitulada a capacitação em Libras, problematizamos a existência ou não de treinamentos para os profissionais que trabalham nos espaços identificados.

\section{ANÁLISE E DISCUSSÕES}

0 Decreto n. 5.626, de 22 de dezembro de 2005, descreve as pessoas surdas como "aquela[s] que, por terlem] perda auditiva, compreende[m] e interage[m] com o mundo por meio de experiências visuais, manifestando sua cultura principalmente pelo uso da Língua Brasileira de Sinais - Libras." (BRASIL, 2005). 0 referido Decreto reconhece, também, a obrigatoriedade do tradutor/intérprete de Língua Brasileira de Sinais/Língua Portuguesa nas instituições de ensino, assegurando, assim, o acesso à informação, à comunicação e 
à educação aos surdos. Nesse sentido, Lacerda (2009, p. 145) expõe a crescente demanda por profissionais especializados em Língua de Sinais, no âmbito educacional, destacando que têm "papel fundamental no processo de aprendizagem das pessoas surdas." Cumpre ressaltar que a possibilidade de pensar e operacionalizar situações em que as trocas comunicativas contem com a presença de tradutor/intérprete de Língua Brasileira de Sinais/ Língua Portuguesa somente pode ser materializada a partir de uma perspectiva bilíngue (KELMAN; LAGE; ALMEIDA, 2015) para os surdos. 0 reconhecimento linguístico recente da Libras, em 2002, constituiu um marco importante para que a Libras e a Língua Portuguesa escrita pudessem produzir sujeitos surdos bilíngues e para que fossem criadas as condições de acessibilidade nessa língua.

Embora não tenhamos dados específicos, o volume crescente de estudos que têm na tradução/interpretação seu foco de análise mostra que a educação vem se ocupando, em certa medida, com o provimento de tradutores/intérpretes para mediar a comunicação entre surdos e ouvintes. No entanto, a ausência do tradutor/intérprete de Língua Brasileira de Sinais/Língua Portuguesa para o atendimento de outras demandas dos surdos tem dificultado a sua inclusão. Uma pesquisa realizada por Pereira (2014) evidencia que a maioria dos profissionais entrevistados em seu estudo atuam na área da educação. A pesquisadora sinaliza que os intérpretes educacionais são procurados pelos surdos para auxiliar na comunicação, em situações relacionadas à saúde, entre outras áreas (PEREIRA, 2014). Cumpre assinalar que, no Brasil, a profissão de tradutor/intérprete de Língua Brasileira de Sinais/ Língua Portuguesa é regulamentada pela Lei n. 12.319, de 1 de setembro de 2010, que prevê o exercício dessa tarefa não apenas no campo da educação, mas nos diferentes espaços sociais, para a promoção de condições materiais para a inclusão (BRASIL, 2010).

Nos estudos que compõem o corpus desta pesquisa foi possível identificar o interesse de diferentes áreas sobre a atuação de tradutores/intérpretes do Língua Brasileira de Sinais/Língua Portuguesa. As pesquisas de Casali (2012), Chaveiro e Barbosa (2005), Pereira (2014), Machado et al. (2013), Neves, Felipe e Nunes (2016) são direcionados aos serviços de saúde. Dias (2013) realizou sua pesquisa nos órgãos públicos; Santos (2008) em diferentes espaços do Município de Santa Maria, RS; Souza et al. (2016) enfocaram no cenário do trânsito; além de Oliveira (2015) e Silva (2015) direcionarem a pesquisa para os museus e centros culturais. Esses estudos evidenciam a falta dos tradutores/intérpretes de Língua Brasileira de Sinais/Língua Portuguesa atuando nos espaços identificados. A ausência desses profissionais faz com que os surdos precisem procurar outras pessoas (família, amigos, etc.) ou tradutores/intérpretes de outras áreas para auxiliarem na comunicação. No Quadro 1 descrevemos esse cenário a partir de excertos das pesquisas: 
Quadro 1 - Presença/Ausência de tradutores/intérpretes de Libras/Língua Portuguesa

Muitas vezes os surdos tinham que levar familiares às consultas ou então pagar um intérprete de Libras para acompanhar o atendimento.'

A falta de intérpretes de LIBRAS constitui-se uma barreira nas instituições de saúde do Brasil, o que torna ainda mais complicada a vida das pessoas com surdez que procuram atendimento ou que solicitam ajuda nestas instituições. ${ }^{2}$

As estruturas institucionais da área da saúde não têm tradutores-intérpretes contratados em seus quadros, mesmo que os serviços já tenham experimentado a falta desses profissionais. ${ }^{3}$

Para facilitar a comunicação entre o surdo e a equipe de enfermagem, a maioria dessas pessoas quando busca atendimentos nos serviços de saúde, sempre o fazem acompanhados, seja por familiares ou amigos. ${ }^{4}$

0 atendimento somente se dá na presença de um intérprete quando o próprio surdo tem a iniciativa de levá-lo, acompanhando-0. ${ }^{5}$

A maior parte dos entrevistados sabem a intervenção do intérprete. [...] falta conscientização, por parte dos órgãos, criando a necessidade de uma legislação que exija pelo menos um funcionário apto a prestar esse tipo de serviço. ${ }^{6}$

Devido à evidente dificuldade na comunicação entre surdos e ouvintes, a solicitação por um número maior de intérpretes é a reivindicação destacada pelo entrevistado, para que o surdo possa circular sem problemas em todas as instituições e instâncias da sociedade. ${ }^{7}$

Os próprios surdos que sentem-se estrangeiros em seus paises de origem, uma vez que os espaços culturais nacionais não apresentam o acesso adequado à informação e comunicação como apresentamos nos nossos resultados. ${ }^{8}$

Hoje essas conquistas legais garantem a presença do intérprete de Libras nas ações de formação para educadores surdos, mas essa lei ainda se mostra tímida. ${ }^{9}$

Fonte: os autores.

Nota: ${ }^{~}$ Casali (2012, p. 46, grifo nosso); ${ }^{2}$ Chaveiro e Barbosa (2005, p. 421, grifo nosso); ${ }^{3}$ Pereira (2014, p. 43, grifo nosso); ${ }^{4}$ Machado et al. (2013, p. 289, grifo nosso); ${ }^{5}$ Neves et al. (2016, p. 160, grifo nosso); ${ }^{6}$ Dias (2013, p. 36, grifo nosso); ${ }^{7}$ Santos (2008, p. 76, grifo nosso); ${ }^{8}$ Silva (2015, p. 22, grifo nosso); ${ }^{9}$ Oliveira (2015, p. 91, grifo nosso).

Em sua dissertação, Oliveira (2015) evidencia que os tradutores/intérpretes de Língua Brasileira de Sinais/Língua Portuguesa não estão presentes nos museus de São Paulo, porém, esses profissionais se encontram, aos poucos, na formação dos educadores surdos que atuam nesses espaços, desenvolvendo ações que possibilitam o acesso dos surdos à arte. Nesse sentido, parece-nos importante pensar na contribuição dos tradutores/intérpretes de Língua Brasileira de Sinais/Língua Portuguesa para a comunicação entre surdos e ouvintes, possibilitando condições de acessibilidade e participação social nos distintos espaços. A acessibilidade constitui um dos princípios para que a inclusão aconteça e merece atenção da 
sociedade, como garantia para a igualdade de oportunidades. Como destaca a Convenção sobre os Direitos das Pessoas com Deficiência (BRASIL, 2011, p. 35), a acessibilidade possibilita

às pessoas com deficiência viver de forma independente e participar plenamente de todos os aspectos da vida, os Estados-Partes tomarão as medidas apropriadas para assegurar às pessoas com deficiência o acesso, em igualdade de oportunidades com as demais pessoas, ao meio físico, ao transporte, à informação e comunicação, inclusive aos sistemas e tecnologias da informação e comunicação, bem como a outros serviços e instalações abertos ao público ou de uso público, tanto na zona urbana como na rural.

Algumas iniciativas pontuais têm contribuído para que as condições de acessibilidade sejam criadas. Jesus (2017) aborda, em seu estudo, a organização de uma Central de Intérpretes de Libras, que segundo o autor, constitui um programa do Governo Federal destinado à garantia de acessibilidade das pessoas surdas nos serviços públicos, por meio da atuação de tradutores/intérpretes de Língua Brasileira de Sinais/Língua Portuguesa. Embora a Central existente no Estado de Santa Catarina, ponto principal do estudo, apresente algumas dificuldades como o limite do horário de atendimento - poucos intérpretes disponíveis e pouca divulgação do serviço - essa é uma iniciativa importante para a promoção da inclusão das pessoas surdas, principalmente na área da Saúde.

0 Decreto n. 5.296, de 2 de dezembro de 2004, destaca os critérios básicos para a efetivação da acessibilidade às pessoas com deficiência. Com relação aos surdos, o referido Decreto estabelece em seu Artigo $6^{\circ}$, inciso III, a necessidade de "serviços de atendimento para pessoas com deficiência auditiva, prestado por intérpretes ou pessoas capacitadas em Língua Brasileira de Sinais - LIBRAS." (BRASIL, 2004). No entanto, os estudos apontam para a ausência dos tradutores/intérpretes de Língua Brasileira de Sinais/Língua Portuguesa atuando em espaços sociais, para além da educação. Mesmo que os entrevistados nas pesquisas, funcionários ouvintes e usuários surdos ressaltem a importância desses profissionais para facilitar a comunicação e o acesso às informações aos surdos, é ponto comum em suas falas que a atividade de tradução/interpretação, quando acontece, é desempenhada por algum amigo ou familiar que acompanha o surdo, ou por um profissional contratado pelo próprio surdo. Não foram observados relatos que indiquem a presença desses profissionais nos espaços pesquisados, o que mostra a fragilidade das condições de acessibilidade.

Dos estudos analisados até aqui, destacamos a recorrência sobre a falta do tradutor/intérprete de Língua Brasileira de Sinais/Língua Portuguesa em distintos espaços sociais. Dessa cena depreende-se que têm se constituído condições de in/exclusão (LOPES; DAL'IGNA, 2007) nos contextos pesquisados. Para as autoras a in/exclusão é caracterizada pela acessibilidade às instalações arquitetônicas, incluindo fisicamente o indivíduo, mas excluindo-o 
das relações que se estabelecem em determinados espaços por onde circula. Entendendo que a comunicação em Libras é fundamental para a inclusão do surdo, passamos a nos perguntar sobre os modos como ocorrem os atendimentos direcionados a ele - na falta de tradutores/intérpretes. Como resposta para essa questão, os materiais analisados indicam que, para atender aos surdos, os funcionários dos diferentes espaços sociais acabam por produzir formas alternativas de comunicação, conforme apresentamos no Quadro 2 :

Quadro 2 - Estratégias de comunicação

Um profissional tentou utilizar a escrita, mas essa estratégia não foi eficaz no atendimento.'

A escrita da língua portuguesa, por ser a segunda lingua do surdo, muitas vezes é de difícil compreensão.

Pelo fato de os surdos muitas vezes não terem problema visual, a escrita poderia ser uma alternativa, mas a realidade não é assim, para eles o português é a segunda lingua, e como qualquer língua estrangeira, é difíil seu aprendizado. ${ }^{3}$

Os métodos mais utilizados nos cinco órgãos públicos participantes da pesquisa são a escrita e a mímica. ${ }^{4}$

Quando ocorre um atendimento, na maioria dos casos a comunicação é feita por meio de escrita, com troca de papéis em linguagem simples. [...] Também acontecem casos onde o funcionário e o surdo não conseguem se comunicar e o cliente saiu sem a informação. ${ }^{5}$

$12(46,15 \%)$ referências ao uso da mímica, 4 (15,38\%) menções ao uso da leitura labial; 8 (30,77\%) referências ao uso da escrita; 1 (3,85\%) referência ao uso do desenho; e 1 (3,85\%) menção à ajuda do intérprete de Libras. ${ }^{6}$

Com tantas dificuldades e limitações no processo de comunicação, eles acabam utilizando outras formas de linguagem não verbal para se expressar, como mímica ou leitura labial, o que impossibilita o relato fidedigno dos problemas de saúde dos surdos, sua história clínica e a descrição dos seus sintomas. ${ }^{7}$

No comércio uso a comunicação escrita, por exemplo, para saber o preço das coisas. ${ }^{8}$

Para LÉO o cinema já é acessivel por possuir legendas em filmes estrangeiros. ${ }^{9}$

Desenvolver um sistema computacional capaz de gerar de forma automática, trilhas alternativas de video com janelas de Libras e Audiodescrição, e distribuir esses conteúdos em salas de cinema, onde os usuários podem utilizar dispositivos móveis de segunda tela para receber esses conteúdos. ${ }^{10}$

Fonte: os autores.

Nota: ${ }^{1}$ Casali (2012, p. 43, grifo nosso); ${ }^{2}$ Casali (2012, p. 44, grifo nosso); ${ }^{3}$ Chaveiro e Barbosa (2005, p. 420, grifo nosso); ${ }^{4}$ Dias (2013, p. 33, grifo nosso); ${ }^{5}$ Lopez (2016, p. 112, grifo nosso); ${ }^{6}$ Machado et al. (2013, p. 287, grifo nosso); ${ }^{7}$ Neves et al. (2016, p. 160, grifo nosso); ${ }^{8}$ Santos (2008, p. 80, grifo nosso); ${ }^{9}$ Melo (2015, p. 48, grifo nosso); ${ }^{10}$ Domingues (2015, p. 53, grifo nosso).

0 conjunto de excertos, agrupados no quadro acima, permite-nos identificar três estratégias principais para a comunicação entre surdos e ouvintes, dada a ausência de 
tradutores/intérpretes: escrita, mímica e a leitura labial. Os estudos de Casali (2012), Chaveiro e Barbosa (2005), Lopez (2016) e Neves, Felipe e Nunes (2016), que realizaram entrevistas com pessoas surdas, concluem que as estratégias utilizadas pelos funcionários nos espaços identificados não constituem um caminho ideal para uma boa comunicação, gerando uma barreira no atendimento dessas pessoas, pois a Libras, considerada a primeira língua dos surdos brasileiros, é raramente utilizada pelos ouvintes para a comunicação. Assim, as condições de acesso dos surdos aos distintos espaços sociais são limitadas pelas barreiras linguísticas. Nessa esteira, alguns estudos ressaltam que a aprendizagem da Língua Portuguesa como segunda língua pode ser difícil para o surdo, pois constitui outra modalidade linguística, diferente da Libras, como destacam os estudos de Casali (2012) e Chaveiro e Barbosa (2005). No entanto, mesmo que as línguas orais e de sinais se constituam a partir de canais diferentes de percepção e emissão de signos linguísticos, com as estratégias adequadas, os surdos são capazes de aprender ambas as línguas.

Como destaca Martins (2016, p. 25), "dentro da sociedade em que vivemos os Surdos são sujeitos que interagem com a sociedade, que consomem produtos e ideologias, que se manifestam nas redes sociais, que buscam informação e conhecimento ao clique de um mouse." Assim, é necessária a presença da Libras nos diferentes ambientes, físicos ou digitais, adequando-os para se tornarem acessíveis a essas pessoas, com condições de participação.

Nesse quadro, destacamos, ainda, os estudos de Domingues (2015) e de Melo (2015), que abordam as dificuldades de acesso das pessoas surdas ao cinema e buscam apresentar as possíveis soluções para a inclusão nesse espaço. No primeiro estudo o objetivo foi desenvolver um sistema que gerasse trilhas alternativas de vídeo em Libras, auxiliando os surdos na compreensão do filme. Os testes realizados foram satisfatórios, porém, conforme sinaliza o autor, são necessárias avaliações mais aprofundadas sobre o sistema. Já o estudo de Melo (2015) expõe a percepção dos surdos quanto à melhor forma de assistir a filmes nas salas de cinema, concluindo que as legendas descritivas em Língua Portuguesa acabam sendo, ainda, as mais viáveis nesse ambiente.

A partir desse frágil conjunto de alternativas utilizadas para a comunicação entre surdos e ouvintes, e dada a sua ineficiência na promoção de uma comunicação eficaz, passamos a buscar, nos estudos analisados, a existência ou não de capacitação em Libras para os profissionais que trabalham nos espaços identificados e a importância do uso dessa língua para ouvintes e surdos. 0 Quadro 3 apresenta os dados retirados dos estudos: 
Quadro 3 - Capacitação em Libras

Constatou-se a ausência de formação nessa área de atuação profissional com os surdos. Muitos dos psicólogos da pesquisa deste autor não sabem Libras, e nunca passaram por treinamento ou aprimoramento nessa área.'

Observa-se que o comportamento não verbal impede um vínculo efetivo entre cliente e profissional, portanto, em sua formação é essencial o aprendizado da LIBRAS como sugerem também os surdos neste estudo.?

A Agência Bancária Caixa Econômica de Goioerê adaptou seu espaço físico e capacitou (Curso de Libras) um de seus funcionários para melhor atender este público. ${ }^{3}$

Análise realizada com os profissionais atuantes nos órgãos públicos apresentados nos gráficos, menos de $10 \%$ possuem conhecimento prévio em LIBRAS, com exceção do Fórum com aproximadamente $15 \%{ }^{4}$

0 coordenador conclui que o treinamento em Libras não é a melhor solução para este tipo de atendimento, pois falta infraestrutura (cursos), a demanda de surdos é pequena (desencorajando a prática da língua), o treinamento tem alto custo e os funcionários estão sujeitos a não permanecer na empresa. ${ }^{5}$

Mesmo entendendo que a demanda de surdos é pequena, a maioria dos funcionários consideram importante para sua atividade o conhecimento da Libras. ${ }^{6}$

Os enfermeiros mostraram-se inseguros ao se relacionarem com os surdos por não conhecerem a lingua de sinais utilizada por eles, pela falta de habilidade em transmitir a informação sobre sua saúde, pela falta de formação durante a carreira acadêmica e até pela inexperiência. ${ }^{7}$

Assim, todos os funcionários que atuam nesses museus, principalmente no núcleo educativo e nos programas de acessibilidade, devem estar a par desta cultura, conhecer minimamente a Libras. ${ }^{8}$

Os sujeitos entrevistados reconhecem a dificuldade dos surdos em integrarem-se plenamente como cidadãos no espaço geográfico da cidade de Santa Maria/RS, em função da falta de interação pela pouca fluência na comunicação entre surdos e ouvintes. ${ }^{9}$

Fonte: os autores.

Nota: 'Casali (2012, p. 38, grifo nosso); ${ }^{2}$ Chaveiro e Barbosa (2005, p. 420, grifo nosso); ${ }^{3}$ Dias (2013, p. 32, grifo nosso); 'Dias (2013, p. 35, grifo nosso); 'Lopez (2016, p. 107, grifo nosso); 'Lopez,(2016, p. 114, grifo nosso); ${ }^{\top}$ Machado et al. (2013, p. 288, grifo nosso); ${ }^{8}$ Oliveira (2015, p. 101, grifo nosso); ${ }^{9}$ Santos (2008, p. 59, grifo nosso).

A existência de cursos de Libras para os profissionais dos espaços identificados nos estudos é pouco significativa. Casali (2012), Dias (2013), Oliveira (2015) e Lopez (2016) apontam capacitações que alguns funcionários da área da Saúde, de uma agência bancária, de museus e de um aeroporto, respectivamente, recebem para melhor atender às pessoas surdas. Porém, eles expressam a necessidade de realizar cursos mais completos e com carga horária mais extensa, pois aprendem apenas o básico, sentindo insegurança e constrangimento por não conseguirem se comunicar com os surdos em Libras, questão levantada também no estudo de Machado et al. (2013). 
Nesse sentido, o Decreto n. 5.626/2005, prevê a capacitação em Libras de funcionários das empresas de serviços públicos e órgãos da administração pública federal, destacando, no Artigo 26, parágrafo $1^{\circ}$, que as instituições "devem dispor de, pelo menos, cinco por cento de servidores, funcionários e empregados capacitados para o uso e interpretação da Libras." (BRASIL, 2005, p. 10). Entretanto, fica evidente, nos estudos, que são poucos os espaços que disponibilizam esses treinamentos, e, quando ofertados, nem sempre são realizados de forma adequada; que a pouca demanda de surdos desestimula a procura por formação em Libras; e, que a oferta de cursos desse tipo ainda é escassa. Cabe acrescentar a esses fatores que a Libras é uma língua que, como todas as outras, exige aprendizagem e exercício constante para que se mantenha viva para o usuário.

Outro aspecto abordado em alguns estudos, sobre a capacitação em Libras, é o despreparo na formação acadêmica dos profissionais. Casali (2012), Chaveiro e Barbosa (2005) e Machado et al. (2013) indicam a necessidade de diferentes cursos de graduação disporem de Libras nas suas matrizes curriculares. Nesse sentido, vale destacar que a Libras como componente curricular - se torna obrigatória em todos os cursos de licenciatura e de Fonoaudiologia, por meio do Decreto n. 5.626/2005, mas não figura nos cursos de bacharelado ou aparece como disciplina optativa. Importa destacar que ainda se fazem necessárias discussões a respeito da inclusão desse componente curricular, também, nos cursos de bacharelado, principalmente nos cursos relacionados ao campo da saúde, área de pesquisa dos autores citados.

Por fim, destacamos que os estudos analisados sinalizam para a importância do conhecimento da Libras, independente da área de atuação, dado o extenso número de surdos que habita o nosso País e a sua circulação na sociedade, de modo a facilitar o acesso desses indivíduos nos distintos espaços sociais e evitar constrangimentos, de ambas as partes, no atendimento. Parece-nos que a comunicação, em Libras, entre ouvintes e surdos - seja de forma direta, seja com a mediação de um tradutor/intérprete - possibilitaria pensar na efetivação de uma sociedade inclusiva.

\section{CONSIDERAÇÕES FINAIS}

Por meio da análise dos estudos selecionados para compor a materialidade desta pesquisa, ficam perceptíveis as dificuldades enfrentadas pelos surdos nos diferentes ambientes onde circulam, com relação ao atendimento recebido nos setores de saúde, nos órgãos públicos, nos museus, nas autoescolas, nos cinemas, entre outros. A falta de comunicação ainda constitui um enfrentamento diário para os surdos, evidenciando que a ausência de 
tradutores/intérpretes de Língua Brasileira de Sinais/Língua Portuguesa; a falta de uma disciplina de Libras na formação acadêmica dos profissionais que fazem o atendimento ao público - ou de cursos de capacitação que possibilitem a aprendizagem da Libras, no exercício da sua função -; e a utilização de estratégias inadequadas de comunicação relacionam-se ao que Lopes e Daligna (2007) descrevem como processos de in/exclusão. Para as autoras, eles se materializam nas relações cotidianas, entre surdos e ouvintes, quando se viabiliza o acesso ao espaço físico, mas não se criam as condições adequadas para a participação, nesse caso, na Língua Brasileira de Sinais.

Os dados analisados nos permitem inferir que, mesmo que as condições de possibilidade para um cenário inclusivo tenham sido postas na década de 1990, a acessibilidade alardeada em campanhas publicitárias e em distintas notícias veiculadas na mídia ainda se encontra frágil ou inexistente nos espaços sociais pesquisados. Nessa cena, há muitas dificuldades quanto à acessibilidade das pessoas surdas nos diferentes espaços sociais, fazendo com que os seus direitos não sejam respeitados como deveriam. A existência de um número importante de leis que procuram garantir o acesso e a inclusão dos surdos, no Brasil, não produz o efeito esperado sobre a população. Para que as mudanças aconteçam, parece-nos necessário repensar as atitudes diante dos surdos, a partir do reconhecimento de suas marcas culturais e da sua condição linguística. A composição de uma cena inclusiva passa pelo reconhecimento das necessidades desse grupo identitário, de modo a produzir uma consciência coletiva sobre ele, pautada na valorização da sua cultura e da sua língua. Entendemos que a promoção de uma acessibilidade em Libras para os surdos depende desse reconhecimento e da produção de políticas públicas adequadas às demandas do grupo.

Por fim, salientamos que, no decorrer de todo o processo de buscas pelos estudos e em decorrência das análises, percebemos que são poucos os trabalhos acadêmicos com ênfase nas pessoas surdas e na acessibilidade em diferentes espaços. Desse modo, parecenos necessário que sejam feitos outros estudos que contemplem essa temática, possibilitando ampliar a compreensão sobre a acessibilidade; motivar a sociedade a reconhecer a cultura surda e a valorizar a Libras; produzir as condições para que esse grupo identitário seja respeitado; e contribuir com a inclusão dessas pessoas, assegurando os seus direitos.

\section{REFERÊNCIAS}

CAIXA lança comercial sobre atendimento em Libras. Agência Caixa de Notícias, 26 ago. 2016. Disponível em: http://www20.caixa.gov.br/Paginas/Noticias/Noticia/Default.aspx?.newsID=527. Acesso em: 13 set. 2017.

BRASIL. Constituição. República Federativa do Brasil de 1988. Brasilia, DF: Senado Federal, 1988. Disponível em: http://www.planalto.gov.br/ccivil_03/constituicao/constituicao.htm. Acesso em: 9 ago. 2017. 
BRASIL. Convenção Sobre os Direitos das Pessoas com Deficiência. Protocolo Facultativo à Convenção sobre os Direitos das Pessoas com Deficiência: Decreto Legislativo n. 186, de 9 de julho de 2008: Decreto n. 6.949, de 25 de agosto de 2009. Braślia, DF: Secretaria de Direitos Humanos: Secretaria Nacional de Promoção dos Direitos da Pessoa com Deficiência, 2011.

BRASIL. Decreto n. 5.296, de 2 de dezembro de 2004. Regulamenta as Leis n. 10.048, de 8 de novembro de 2000 e n. 10.098, de 19 de dezembro de 2000, que estabelece normas gerais e critérios básicos para a promoção da acessibilidade das pessoas portadoras de deficiência ou com mobilidade reduzida, e dá outras providências. Diário Oficial da União, Brasilia, DF, 3 dez. 2004. Disponível em: http://www.planalto.gov.br/ccivil_03/_ato2004-2006/2004/decreto/d5296.htm. Acesso em: 17 jul. 2017.

BRASIL. Decreto n. 5.626, de 22 de dezembro de 2005. Regulamenta a Lei n. 10.436, de 24 de abril de 2002, que dispõe sobre a Língua Brasileira de Sinais - Libras, e o art. 18 da Lei no 10.098, de 19 de dezembro de 2000. Diário Oficial da União, Brasilia, DF, 23 dez. 2005. Disponível em: http://www.planalto.gov.br/ccivil_03/_ato2004-2006/2005/decreto/d5626.htm. Acesso em: 18 jul. 2017.

BRASIL. Decreto n. 6.949, de 25 de agosto de 2009. Promulga a Convenção Internacional sobre os Direitos das Pessoas com Deficiência e seu Protocolo Facultativo, assinados em Nova York, em 30 de março de 2007. Diário Oficial da União, Brasília, DF, 26 ago. 2009. Disponível em: http://www.planalto. gov.br/ccivil_03/_ato2007-2010/2009/decreto/d6949.htm. Acesso em: 19 mar. 2018.

BRASIL. Lei n. 12.319, de 1 de setembro de 2010. Regulamenta a profissão de Tradutor e Intérprete da Língua Brasileira de Sinais - LIBRAS. Diário Oficial da União, Brasilia, DF, 2 set. 2010. Disponível em: http://www.planalto.gov.br/ccivil_03/_ato2007-2010/2010/lei/112319.htm. Acesso em: 6 nov. 2017.

BRASIL. Lei n. 13.146, de 6 de julho de 2015. Institui a Lei Brasileira de Inclusão da Pessoa com Deficiência (Estatuto da Pessoa com Deficiência). Diário Oficial da União, Brasília, DF, 7 jul. 2015. Disponível em: http://www.planalto.gov.br/ccivil_03/_ato2015-2018/2015/lei/113146.htm. Acesso em: 9 ago. 2017.

BRASIL. Ministério do Planejamento, Orçamento e Gestão. Censo Demográfico 2010: Características gerais da população, religião e pessoas com deficiência. Rio de Janeiro: Instituto Brasileiro de Geografia e Estatística, 2012. Disponível em: https://www.bge.gov.br. Acesso em: 23 fev. 2018.

CASALI, D. 0 atendimento psicológico ao surdo usuário da LBBRAS no município de Itajaí-SC. 2012.

Dissertação (Mestrado em Saúde e Gestão do Trabalho) - Universidade do Vale do Itajaí, Itajaí, 2012. Disponivel em: http://siaibib01.univali.br/pdf/Debora\%20Casali2012.pdf. Acesso em: 13 set. 2017.

CHAVEIRO, N.; BARBOSA, M. A. Assistência ao surdo na área de saúde como fator de inclusão social. Revista. Esc. Enf., p. 417-422, mar./jul. 2005. Disponivel em: http://www.ee.usp.br/reeusp/upload/ pdf/62.pdf. Acesso em: 12 mar. 2018. 
DIAS, V. A. A. Atendimento aos surdos pelos órgãos públicos. 2013. Monografia (Pós-graduação em Educação: Métodos e Técnicas de Ensino, Modalidade de Ensino a Distância) - Universidade Tecnológica Federal do Paraná, Medianeira, 2013. Disponivel em: http://repositorio.roca.utfpr.edu.br/jspui/ bitstream/1/4669/1/MD_EDUMTE_II_2012_17.pdf. Acesso em: 1 set. 2017.

DOMINGUES, L. A. Acessibilidade em cinemas digitais: uma proposta de geração e distribuição de Libras e Audiodescrição. 2015. Dissertação (Mestrado em Informática) - Universidade Federal da Paraiba, João Pessoa, 2015. Disponível em: tede.biblioteca.ufpb.br/bitstream/tede/7852/2/arquivototal.pdf. Acesso em: 16 mar. 2018.

GAZZONI, M. Para ampliar acessibilidade, Gol testa atendimento em Libras. Estadão, 12 jun. 2014. Disponivel em: http://economia.estadao.com.br/noticias/geral.para-ampliar-acessibilidade-gol-testa-atendimento-em-libras-imp-,1510527. Acesso em: 13 set. 2017.

JESUS, R. B. “Ei, aquele é o intérprete de Libras?" Atuação de intérpretes de LIBRAS no contexto da saúde. 2017. Dissertação (Mestrado em Estudos da Tradução) - Universidade Federal de Santa Catarina, Florianópolis, 2017. Disponivel em: https://repositorio.ufsc.br/handle/123456789/182062. Acesso em: 15 mar. 2018.

KELMAN, Celeste Azulay; LAGE, Aline Lima da Silveira, ALMEIDA, Simone D'Avila. Bilinguismo e educação: práticas pedagógicas e formação de professores. Revista espaço, Rio de Janeiro: INES, n. 44, jan./jul. 2015.

LACERDA, C. B. F. Tradutores/intérpretes de Língua Brasileira de Sinais: formação e atuação nos espaços educacionais inclusivos. Cadernos de Educação, Pelotas, v. 36, maio/ago. 2009.

LOPES, M. C.; DAL'IGNA, M. C. (org.). In/Exclusão: Nas tramas da escola. Canoas: Ed. ULBRA, 2007.

LOPES, M. C. et al. Inclusão e biopolítica. São Leopoldo: Caderno HHU Ideias, ano 8, n. 144, 2010.

LOPES, M. C.; VEIGA-NETO, A. Marcadores culturais surdos: quando eles se constituem no espaço escolar. Perspectiva, Florianópolis, v. 24, jul./dez. 2006. Edição especial.

LOPEZ, M. H. Análise do atendimento aos surdos no contexto aeroportuário sob a ótica da ergonomia: um estudo de caso em um aeroporto em Santa Catarina. 2016. Dissertação (Mestrado em Engenharia de Produção) - Universidade Federal de Santa Catarina, Florianópolis, 2016. Disponível em: https:// repositorio.ufsc.br/bitstream/handle/123456789/175815/345517.pdf? sequence=1\&isAllowed=y. Acesso em: 11 mar. 2018.

MACHADO, W. C. A. et al. Língua de sinais: como a equipe de enfermagem interage para cuidar de clientes surdos? Journal of Research Fundamental Care On Line, v. 5, p. 283-292, jul./set. 2013. Disponivel em: http://www.seer.unirio.br/index.php/cuidadofundamental/article/viewFile/2065/pdf_870. Acesso em: 27 fev. 2018. 
MARCONI, M. A.; LAKATOS, E. M. Técnicas de Pesquisa: planejamento e execução de pesquisas, amostragens e técnicas de pesquisas, elaboração, análise e interpretação de dados. São Paulo: Atlas, 2002.

MARTINS, G. P. T. C. Por um Brasil mais acessivel: espalhe os sinais - LIBRAS. 2016. Dissertação (Mestrado em Diversidade e Inclusão) - Universidade Federal Fluminense, Niterói, 2016.

MELO, J. V. Percepções do público surdo sobre a acessibilidade no cinema. 2015. Dissertação (Mestrado em Saúde, Interdisciplinaridade e Reabilitação) - Universidade Estadual de Campinas, São Paulo, 2015. Disponivel em: http://repositorio.unicamp.br/bitstream/REPOSIP/309755/1/Melo_JulianaValeria_M. pdf. Acesso em: 11 ago. 2017.

MINAYO, M. C. S.; DESLANDES, S. F.; GOMES, R. (org.). Pesquisa Social: Teoria, Método e Criatividade. Petrópolis: Vozes, 2002.

NEVES, D. B.; FELIPE, I. M. A.; NUNES, S. P. H. Atendimento aos surdos nos serviços de saúde: acessibilidade e obstáculos. Revista Infarma Ciências farmacêuticas, v. 28, p. 157-165, jun./set. 2016. Disponível em: http://oajinet/articles/2016/3425-1475592302.pdf. Acesso em: 26 fev. 2018.

OLIVEIRA, M. Cultura e inclusão na educação em museus: processos de formação em mediação para educadores surdos. 2015. Dissertação (Mestrado em Museologia) - Universidade de São Paulo, São Paulo, 2015. Disponivel em: www.teses.usp.br/teses/disponiveis/103/103131/.../MargaretedeOliveiraREVISADA.pdf. Acesso em: 30 mar. 2018.

PEREIRA, P. C. A. Tradutores-intérpretes de LBRAS na Saúde: o que eles nos contam sobre questões éticas em suas práticas. 2014. Tese (Doutorado em Saúde Pública) - Universidade de São Paulo, São Paulo, 2014. Disponivel em: http://www.teses.usp.br/teses/disponiveis/6/6135/tde-04082015-133658/ pt-br.php. Acesso em: 03 mar. 2018.

SANTOS, A. T. 0 espaço geográfico, os surdos e o(s) processo(s) de inclusão/exclusão social na cidade de Santa Maria/RS. 2008. Dissertação (Mestrado em Geografia) - Universidade Federal de Santa Maria, Santa Maria, 2008. Disponivel em: http://repositorio.ufsm.br/handle/1/9283. Acesso em: 17 mar. 2018.

SILVA, J. P. F. Acessibilidade aos cegos e surdos nos museus e centros culturais da cidade do Rio de Janeiro. 2015. Dissertação (Mestrado em Diversidade e Inclusão) - Universidade Federal Fluminense, Niterói, 2015.

SOUZA, V. M. et al. A inclusão de surdos no trânsito. Revista CEFAC, p. 677-687, maio/jun. 2016. Disponivel em: http://www.scielo.br/pdf/rcefac/v18n3/1982-0216-rcefac-18-03-00677.pdf. Acesso em: 27 fev. 2018.

Endereços para correspondência: Rua Uruguai, 434E, Apto. 202, Centro, 89801-570, Chapecó, Santa Catarina, Brasil; talinepchaves@gmail.com 